\title{
A Study of Temporal-spatial Evolution Model of Grassland Fire Behavior and Fire Risk Warning Based on MCD45
}

\author{
Yulong Bao ${ }^{1,2,3}$, Yuhai Bao ${ }^{1,2}$, Lai Quan ${ }^{1,2,3}$, Yong Mei ${ }^{1,2,3}$, Enliang Guo ${ }^{1,3}$, \\ Zhijuan Bai $^{4}$, Suriguga ${ }^{1}$ \\ ${ }^{1}$ College of Inner Mongolia normal university geography science, Hohhot 010022, China \\ ${ }^{2}$ Inner Mongolian key laboratory of remote sensing and geographic information system, Hohhot \\ 010022, China \\ ${ }^{3}$ Inner Mongolian key laboratory of Disaster and Ecological Security on the Mongolia Plateau, \\ Hohhot 010022, China \\ ${ }^{4}$ Inner Mongolia normal university library, Hohhot 010022, China
}

\section{Abstract}

With the adoption of MCD45 product in a consecutive twelve years, the spatial evolution model of fire behavior in the study area is analyzed and the spatial and temporal variation rule in interannual and seasonal duration is mastered. On that basis and starting from the principle of grassland fire combustion mechanism, the index of the source of fire, the combustible state index and the fire environmental index are built. Through comprehensive analysis the grassland fire danger index is obtained, with the fire danger classified into five levels by using the risk matrix method. To verify the accuracy of the model, the fire point data on March 22nd, 2012 is tested and the accuracy proves to be $71 \%$. The result shows that the grassland fire danger warning method can be applied to warning work in grassland regions and can efficiently improve the accuracy of grassland fire warning, which denotes great practical significance in domestic grassland fire prevention and control work.

Keywords: MCD45 product; Fire behavior; Grassland fire danger; Grassland fire danger warning method.

\section{Introduction:}

China is a country with rich grassland resources with an area of nearly $3.9 \times 10^{8}$ square kilometers, which occupies $11.9 \%$ and $40 \%$ of the world grassland area and national land area respectively. They are widely distributed in the west of northeast plain, Inner Mongolia, mountainous areas of northwest desert region and the Tibetan plateau area, among which Songnen grassland is with the best hydrothermal conditions. Blessed with abundant good-quality pasture and lush plants, Songnen grassland is an excellent grazing and moving grassland with a high productivity. It is also one of the ten important pastoral areas in China, occupying an important position in domestic temperate grassland. With the growth of population density in Songnen grassland area, grassland fire disasters and other disasters caused by human activities are even more frequent and ecological deterioration are increasingly serious.

Currently, the majority of fire science researchers at home and abroad take forest fires as the main object of study, while the research into grassland fires is lagging behind. From the perspective of research into forest fire danger warning, generally it has experienced three 
stages: (1) the $1960 \mathrm{~s}$ and $1970 \mathrm{~s}$, researchers mainly use meteorological factors as the factor of the fire danger prediction and meteorological elements as the main parameters of the forecast respectively; (2) the $1980 \mathrm{~s}$ and $1990 \mathrm{~s}$, the development of remote sensing technology and geographic information system greatly promoted the research and development of fire danger index, and the multi-factorial fire danger forecast was started; (3) since 1990s, with the development of the network and remote sensing monitoring, domestic and foreign scholars consider the combustible conditions, meteorological conditions, terrain and other factors overall to calculate the fire danger index, thus the fire danger index can be used more conveniently and more quickly.

With the development of fire danger warning technology and remote sensing technology, it has become one of the primary means of fire disaster research to use fire products globally or regionally to extract fire disaster information, thus monitoring and managing the fire disaster situation. For example, the International Geosphere-Biosphere Programme-Fire Working Group (IGBP-FWG) uses the data of Advanced Very High Resolution Radiometer (NOAA AVHRR) to develop global fire products with a one-kilometer scale in order to monitor the diurnal variation of global fire incidents $^{[1]}$ (FLASSE S, CECCATO P.1996). The Global Burned Figure, i.e GlobScar, was developed by the European Space Agency (ESA) in $2000^{[2]}$ (Simon et al, 2004). The Joint Research Centre (JRC) of the European Commission carried out the Global Burnt Area project GBA $2000^{[3]}$ (Kevin, 2004). So far there are L3JRC ${ }^{[4]}$ (Tansey et al, 2008), GlobCarbon ${ }^{[5]}$ (Plummer ea al, 2006 ), MCD45 $5^{[6]}$ (Justice et al, 2002), $\mathrm{AQS}^{[7]}$ (Opazo \& Chuvieco, 2009) and other fire products, among which L3JRC and GlobCarbon are upgraded versions of the GBA2000 and GlobScar respectively, while the MCD45 and Area QuemadaSudamerica (AQS) are MODIS products. By comparing the accuracy of thefour products, Jesús Anaya et found that at the level of one-kilometer spatial resolution, L3JRC is more appropriate, but comprehensively speaking, MCD45is the best and is superior to other products $^{[8]}$. Helen M.de Klerk et al pointed out that the MCD45 data is with lower commission errors and higher user accuracy ${ }^{[9]}$. By verifying MCD45, L3JRC and GlobCarbon products separately, Roy et al found the MCD45 is with higher cartographic precision, which makes locating surface-fire within a small area possible ${ }^{[10]}$.

With the adoption of MCD45 burned area product and on the analytical basis of the spatial and temporal distribution patterns of fire behavior in the study area, the paper explored the grassland fire danger warning method by comprehensively utilizing multi-source data.

\section{The general situation of the study area and data processing}

\subsection{The general situation of the study area}

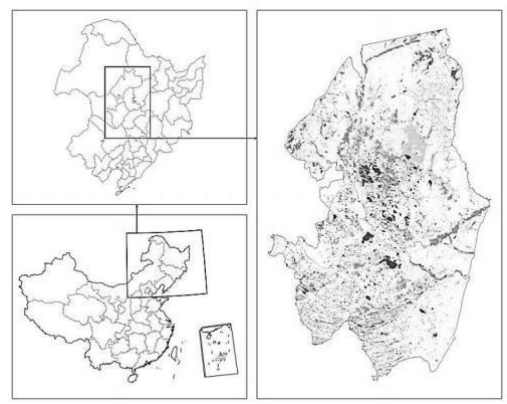

Fig.1 The study area

The research took Songnen grassland as the study area(Figure1), which is located in the middle part of Northeast China between $43^{\circ} 30^{\prime} \sim 48^{\circ} 05^{\prime} \mathrm{N}$ and $122^{\circ} 12^{\prime} \sim 126^{\circ} 20^{\prime} \mathrm{E}$. It is surrounded by mountains on three sides, with DaxinganlingMountains to the west, Elehuli and Xiaoxing'anling Mountains to the north and Zhangguangcailing ridge within the ChangbaishanMountain to the east. Low hills 
lying to the south are Songliao watershed,which is a plain mainly formed by alluviation of Songhuajiang river, Nenjiang river, Taoerhe river and Huolinhe river. It is also a major part of one of the three great plains in China-the Northeast Plain.

\subsection{Data source and data processing}

The MODIS burned area product (MCD45) used in this study was the synthesized Level 3 product of the data from satellite Terra and satellite Aqua, which belonged to Earth Observing System (EOS). The spatial resolution was 500 meters with sinusoidal projection being used. The data was available for download from the official website of the U.S. National Aeronautics and Space Administration (NASA) (http://www.nasa.gov/). Julian date represents Pixel value of burned area, a value of 0 means it is yet to be determined whether there is fire area, data loss, data corruption or cloudy sky while a value of 1-366 represents the Burned date. The image of quality assessment (QA) information was also provided.

Other basic data, including vegetation type maps, digital elevation model (DEM) data and the data of 27 meteorological stations within and around the study area, were all obtainable from the China Meteorological Data Sharing Service (http://cdc.cma.gov.cn).

MCD45 product in a total of 12 years from 2000 to 2011 were used in the study, with H26V04 and H27V04 being the identification of product. MRT (MODIS projection tool) and Cygwin software were used in combination to write a batch program in order to conduct projection transformation and inlaid processing. The Phyton language was adopted to write the ARCGIS scriptlet program, which was intended to extract Burned area information. The fire point extraction was completed and processed.

\section{Research Method}

The trend of temporal evolution and the mode of spatial evolution of fire behavior were analyzed by combining traditional statistical method and the spatial statistical method developed for the geographical event. Annual variation and seasonal variation were mainly counted in terms of time, spatial distribution mode of fire point and variation mode of hotspot and coldspot were mainly analyzed in terms of space.

"Grassland Fire Hazard or Danger", in other words, is the risk of grassland fire, the degree of the risk of fire in a certain region and a certain period of time, or the possibility of fire[11]. It is influenced by fire source, the condition of the combustibles and fire environment. When there are combustibles in the grassland and the climate is fit for grassland fire, whether the grassland is on fire or not is decided by fire source.

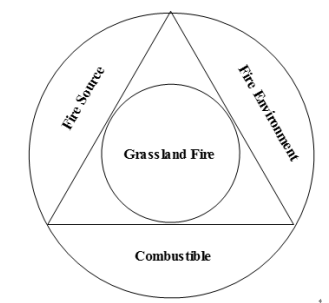

Fig. 2 The structure of grassland burning link

According to the Grassland Burning Link theory (as is showed in Fig.2) ${ }^{[12]}$, fire source index, condition of combustible index, fire environment index were constructed respectively by taking full account of three prerequisites on the grassland fire, that is fire source, combustible and fire environment. The spatial distribution of every index was realized by using the technology of spatial analysis and the comprehensive grassland fire hazard index model was built.

\subsection{Fire Source Index}

Human-caused fire source and naturalignition source are two main fire sources. The natural ignition source is caused by natural phenomenon, for example, thunder, lightning 
and so on.The human-caused fire source is the source of grassland fire caused due to human activities. More than $98 \%$ of grassland fire hazards are caused by human activity, according to the statistics. The population density in grassland is large and their frequency of using fire is high, therefore, the fire source density is also high. However, there is hardly any correlation between population density and the spatial evolution of fire according to the contrast between fire behavior spatial evolution mode and population density in chapter 3 . Therefore the fire source index cannot be indicated by population density or road network density. The author holds that human living environment and the mode of production are the direct reasons for the high levels of fire behaviors aggregation. For example, the reason for the high density of fire behavior in the grassland area in spring is that herdsmen burn the wastelands and in autumn is that farmers burn straws.

The spatial statistics on fire point over the past 12 years in this research area show that there is a big difference between the frequency and spatial distribution of fire behavior every ten days, which can reflect the distribution of fire source. So the spatial distributions on fire point every ten days indicate fire source index which can be divided into 5 scales in the way of standard deviation. The criterions of division are given as:

$$
\begin{array}{lr}
\text { 1: } & \text { Fire source index } \leqq \mu-\sigma \\
2: & \mu-\sigma<\text { Fire source index } \leqq \mu \\
\text { 3: } & \mu<\text { Fire source index } \leqq \mu+\sigma \\
\text { 4: } & \mu+\sigma<\text { Fire source index } \leqq \mu+2 \sigma \\
5: & \text { Fire source index }>\mu+2 \sigma
\end{array}
$$

Where, $\mu$ is the significant mean score of fire point, $\sigma$ is the standard deviation.

\subsection{Combustible State Index}

Combustible is a material prerequisite for grassland fire. The standing stock andflammability of combustible determine formation and spread of the grassland fire. So two indicators, that is carrying capacity and combustibility of combustible were chose among combustible state index for this study.

Combustible carrying capacity is the absolute dry weight of combustible per unit area, and it directly affects formation, spread and intensity of fire. This study used models for estimation of grassland production based on MODIS data in Songnen Plain which was established by Luo Ling et al [13]. The following is the function:

$$
y=e^{8.05-1.09 / n d v i} \quad(\mathrm{R}=0.81) \quad(1)
$$

Combustible carrying capacityin this study was obtained by applying formula (1) to calculate fresh grass production and referring to the ratio of the fresh weight to dry weight of Songnen Plain [14].

The indicator of grassland combustibility was replaced by the frequency of fire behavior on difference grassland.

The formula for calculating combustible state index is:

$$
\mathrm{CSI}=\mathrm{P} 1+\mathrm{P} 2
$$

In formula (2), CSI represents combustible state index, P1 and P2 represent combustible carrying capacity and combustibility respectively. Combustible state index is ranked with method of standard deviation classification.

\subsection{Fire Environment Index}

Fire environment is an important prerequisite for grassland fire, and it directly or indirectly impacts formation and spread of the fire. It includes grassfire climate and topographical environment. Many factors of grassfire climate affect combustible moisture such as temperature, relative humility, rainfall, wind speed and so on. Generally, when the rainfall is high and the moisture of the combustible is high, the combustible is nonflammable. When the temperature is high, the rainfall is low and wind speed is high, the 
combustible is flammable. This study adopted grassland fire danger index which was published by National Meteorological Center of China to calculate grassfire climate [15]. This fire danger index was called grassland fire risk index or WI (formula 5). It was based on the weighted average means of the results of Baron Davis Project (formula 3) and the revised Baron Davis Project (formula 4) which had been studied by Los Angelesexperiment station of American, and revised according to surface conditions and a rainfall coefficient. A more detailed procedure is described below.

$$
\begin{array}{r}
U=I_{v}(v)+I_{T}(T)+I_{\mathrm{r}}(\mathrm{rh})+I_{\mathbb{m}}(\mathrm{m}) \\
U^{\prime}=I_{v}^{\prime}(v)+I_{T}^{\prime}(T)+I_{\mathrm{r}}^{\prime}(\mathrm{hh})+I_{m}^{\prime}(m) \\
W I=\left(A U+B U^{\prime}\right) \times C_{s} \times C_{r}
\end{array}
$$

In these formulas, $\mathrm{v}$ is the wind speed $(\mathrm{m} / \mathrm{s})$ at 14 o'clock, $\mathrm{T}$ is the temperature $\left({ }^{\circ} \mathrm{C}\right)$ at 14 o'clock, rh is the relative humility (\%) at 14 o'clock, $\mathrm{m}$ is the number of consecutive days without rain (day), and $I_{v}(v) \ldots I_{m}^{\prime(m)}$ are the single-factor indexes which are obtained from the standard scales (table1). CS is the revised surface condition index, and value range is $0 \sim 1$; $\mathrm{Cr}$ is the revised rainfall coefficient, and if there was rainfall on that day, the value of $\mathrm{Cr}$ is 0 , otherwise it is 1 . Weight coefficient A and B are 0.3 and 0.7 respectively.

As study area was the plain whose slopes and aspects hardly change, topographical environment indexes belong to the same category after calculating. Hence this calculation procedure was ignored.

\subsection{Fire Danger Index}

Fire danger index is a specific measurement of degree of grassfire risk, and a comprehensive function of fire source, combustible and fire environment. The calculation formula follows:

$\mathrm{FDI}=\mathrm{FSI} \times \mathrm{CSI} \times \mathrm{FEI} \quad(6)$

In this formula: FDI stands for fire dangerindex, and the bigger the index is, the larger possibility of grassland fire.

Among indicators of fire source, combustible and fire environment, fire source index was the most uncertain one. So this study firstly conducted an overlay analysis on combustible condition index and fire environment index, then divided the results into five ratings by using risk rating matrix. Next, the results and fire source index were also analyzed by using method of overlay analysis. The final results were also divided by using risk rating

\begin{tabular}{|c|c|c|c|c|c|c|c|}
\hline $\begin{array}{l}\text { Wind } \\
\text { speed } \\
(\mathrm{m} / \mathrm{s})\end{array}$ & $I_{v}^{\prime}(v)$ & $\begin{array}{c}\text { temperature } \\
\left({ }^{\circ} \mathrm{C}\right)\end{array}$ & $I_{T}^{\prime}(T)$ & $\begin{array}{c}\text { Relative } \\
\text { humility } \\
(\%)\end{array}$ & $I_{\mathrm{r}}^{\prime}(\mathrm{rh})$ & $\begin{array}{c}\text { Number of } \\
\text { consecutive days } \\
\text { without rain (day) }\end{array}$ & $I_{m}^{\prime}(m)$ \\
\hline $0 \sim 1.5$ & 3.846 & $<5$ & 0 & $>70$ & 0 & 0 & 0 \\
\hline $1.6 \sim 3.4$ & 7.692 & $5 \sim 10$ & 4.61 & $60 \sim 70$ & 3.076 & 1 & 7.692 \\
\hline $3.5 \sim 5.5$ & 11.538 & $11 \sim 15$ & 6.1 & $50 \sim 59$ & 6.153 & 2 & 11.538 \\
\hline $5.6 \sim 8.0$ & 15.384 & $16 \sim 20$ & 9.23 & $40 \sim 49$ & 9.23 & 3 & 19.23 \\
\hline $8.1 \sim 10.8$ & 19.236 & $21 \sim 25$ & 12.5 & $30 \sim 40$ & 12.307 & 4 & 23.076 \\
\hline $10.9 \sim 13.9$ & 23.076 & $>25$ & 15.384 & $<30$ & 15.384 & 5 & 26.923 \\
\hline $14.0 \sim 17.2$ & 26.923 & & & & & 6 & 30.7 \\
\hline \multirow[t]{2}{*}{$>17.2$} & 30.9 & & & & & 7 & 34.615 \\
\hline & & & & & & $>8$ & 38 \\
\hline
\end{tabular}
matrix.

Table1. The revised standard scale of fire weather factors and their indexes in Baron Davis 


\section{Analysis of Results}

\subsection{Spatial Evolution Analysis of Fire Behavior}

MCD45 is a sensing product synthesized after 16 days. Therefore, according to the characteristics of MCD45, 16 days is defined as a period and a year is divided into 23 periods. SPSS18.0 was employed to count the time change of fire behavior and to find out the annual variation (as is showed in Fig.3) and seasonal variation (as is showed in Fig. 4) of fire behavior.

The results of annual variation show that there is an increasing trend on fire behavior in research area, but the increase is not significant; in terms of seasonal variation, there is an apparent change on fire behavior. The chart clearly shows that fire behaviors often happen in spring and autumn, mainly $4 \sim 10$ periods in spring, 14 20 in autumn. Area and proportion of fire behavior in spring and autumn respectively is $6196.51 \mathrm{~km} 2,5470.00 \mathrm{~km} 2$ and $53.11 \%$, $46.89 \%$.

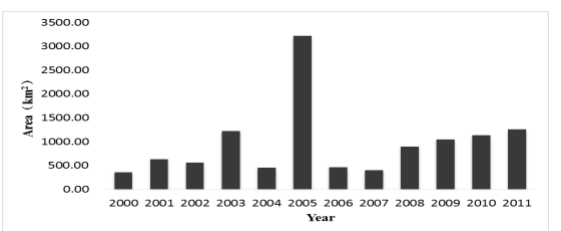

Fig. 3 Annual variation on fire behavior

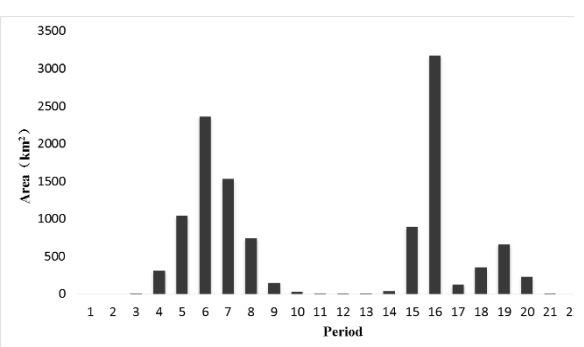

Fig. 4 Seasonal (period) variation on fire behavior

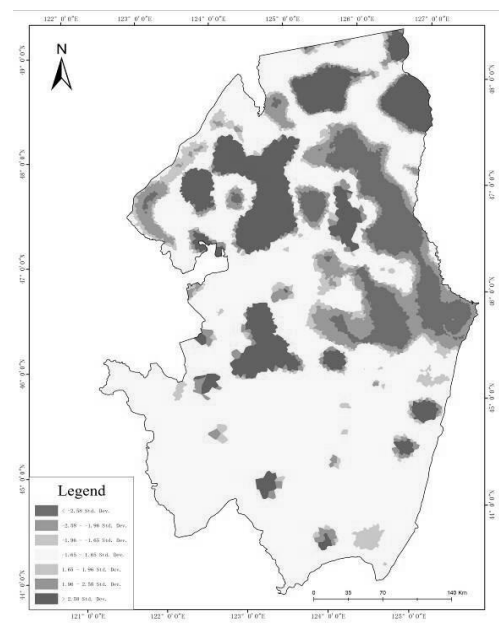

Fig. 5 An analysis of the hotspot of fire behavior

The spatial mode and hot and cold distribution of fire behavior are showed in Fig. 5. There exists highly dense distribution of fire point in the research area in terms of space. In this figure, the high incidence area and low incidence area can be accurately positioned. The significant difference on fire behavior in terms of time and space indicates that fire behavior has close relationship with residents' living habits and mode of production. This finding is also important to grassland fireproof work.

\subsection{Case Study on Fire Risk Warning}

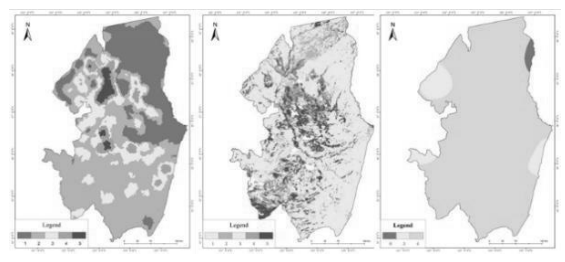

Fig. 6 Fire source index, Fig. 7 Index of condition of

combustible, Fig. 8 Fire environment index

In order to test grassland fire risk index, data about fire point in March, 2012 are extracted. When it comes to 82 nd day (22, Mar), fire point is the most frequent, judging from the frequency chart of fire point. Therefore, the Meteorological data and other related data in 22, 
Mar are collected in order to calculate the fire risk index.

It can be seen that 22, March belongs to the 6th period. By calculating hotspot spatial distribution of fire behavior on 6th period and classifying the distribution, the figure of fire source index (as is showed in Fig. 6) is obtained.

The following Fig. 7 and Fig. 8 are made according to calculation methods of combustible condition index and fire environment index. Then the grassland risk index in 22, March (as is showed in Fig. 9) is calculated by formula 6 .

Comparing the data of fire point on 22, Mar, 2012 with grassland risk index, it can be seen that there are 45 fire points in the highest fire risk area, 16 in less higher fire risk area, 19 in high fire risk area, 3 in low fire risk area, 30 in the lowest fire risk area. Their proportion is shown in Fig.10. It is shown that the number of fire point in the high fire risk area, higher fire risk area and the highest fire risk area takes up $71 \%$ of the total number, which indicates that the accuracy of fire risk warning is relatively high.

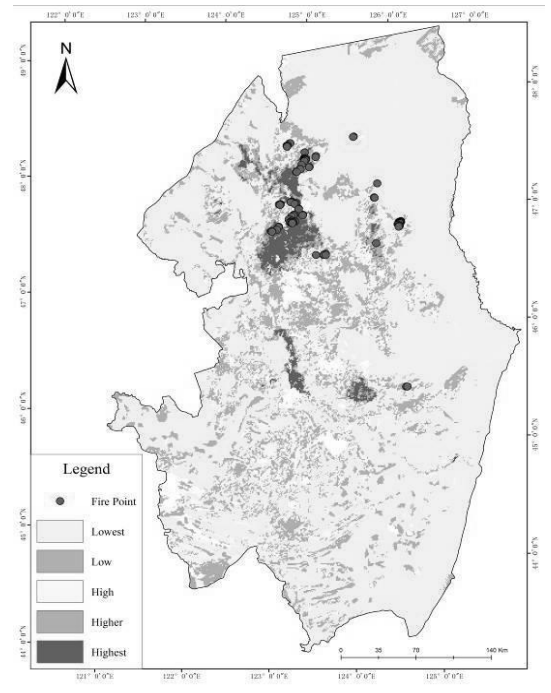

Fig. 9 Grassland fire risk index on 22, Mar, 2012

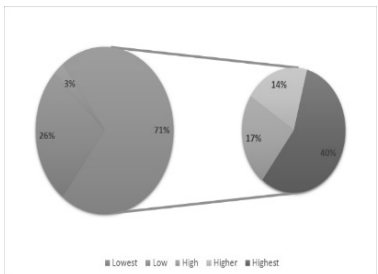

Fig. 10 The proportion of fire point and grassland fire risk

This article analyzes the temporal-spatial evolution mode of fire behavior on Songnen grassland by using the product-MCD45. It also discusses comprehensive warning method on grassland fire risk based on that mode, that is to say, it has constructed fire source index, combustible state index and fire environment index based on grassland burning mechanism. It also calculates grassland fire risk index on 22 , Mar, 2012 by comprehensively applying spatial mode data on fire behavior, vegetation index, types of grassland and meteorological data. The accuracy can arrive at $71 \%$ through testing. The result shows that the grassland fire danger warning method can be applied to warning work in grassland regions and can efficiently improve the accuracy of grassland fire warning, which denotes great practical significance in domestic grassland fire prevention and control.

\section{Acknowledgements}

This work was supported by the National Natural Science Foundation of China under Grant (Grant No. 41561099), the National Natural Science Foundation of China under Grant (Grant No. 61631011)and the Inner Mongolia science and technology project (201702116).

\section{References:}

[1] Flasse S P,Ceccato P, A contextual algorithm for AVHRR fire detection. International Journal of Remote Sensing, 1996,17: 419-424. 
[2] SimonM, PlummerS, Fierens F, Hoelzemann J, Arino O. Burnt area detection at global scale using ATSR-2:The GLOBSCAR products and their qualification. Journal of Geophysical Research, 2004, 109(D14S02):1-16.

[3] Kevin T, et al. Vegetation burning in the year 2000: Global burned area estimates from SPOT VEGETATION data. Journal of Geophysical Research, 2004, 109 ( D14S03):1-22.

[4] Tansey K, Grégoire J, Defourny P, Leigh R, PekelJ-F, van BogaertE, BartholoméE, BontempsS.A new global multi-annual (2000-2007) burned area product at $1 \mathrm{~km}$ resolution and daily intervals. Journal of Geophysical Research,2008, 35(L01401): $1-6$

[5] Plummer S,Arino O, Simon M, W. Steffen W. Establishing a earth observation product service for the terrestrial carbon community: the globcarbon initiative. Mitigation and Adaptation Strategies for Global Change, 2006, 11(1):97-111.

[6] Justice C, Giglio L, Korontzi S, Owens J, Morisette J, Roy D, Descloitres J, Alleaume S, Petitcolin F, Kaufman Y. The MODIS fire products. Remote Sensing of Environmen, 2002, 83: 244-262.

[7] Opazo S, Chuvieco E. Cartografía de áreasquemadas en Sudamérica: Detección de píxelessemilla. Revista de Teledetección, 2009,32:50-71.

[8] Anaya J, Chuvieco E.Accuracy assessment of burned area products in the Orinoco basin. Photogrammetric Engineering and Remote Sensing, 2012, (78):53-60.

[9] Klerk H, Wilson A, Steenkamp K. Evaluation of satellite-derived burned area products for the fynbos, a mediterranean shrubland. International Journal of Wildland Fire, 2011, (21):36-47.

[10] Roy D, Boschett P. Southern Africa Validation of the MODIS, L3JRC and GlobCarbon Burned Area Products. J. IEEE transactions on Geoscience and Remote Sensing, 2009, 47(4): 1032 - 1044.

[11] Zhang JQ, Tong ZJ, Song ZS, et al. Risk management of grassland fire disaster: innovative model and Chinese strategy choice. Proceedings of Chinese Prataculture Forum, 2006, 583-593.

[12] Zhen H N. Network of Forest Burning Links. Northeast Forestry University Press, Harbin, 2003.

[13] Luo L, Wang ZM, Ren CY, et al. Models for estimation of grassland production and spatial inversion based on MODIS data in Songnen Plain. Transactions of the Chinese Society of Agricultural Engineering,
2010,(5):182-187.

[14] The Department of Animal Husbandry and Veterinary and the General Station of Animal Husbandry and Veterinary of the Ministry of Agriculture, P. R. China. Rangeland Resources of China. Beijing: Chinese Science and Technology Press, 1996. 108-123.

[15] Niu RY, Zhai PM, She WM. Applied Research on Forest Fire Danger Weather Index. J Journal of Applied Meteorological Science, 2007, (4): 479-489. 